\title{
Prediction based on preoperative opioid use of clinical outcomes after transforaminal lumbar interbody fusions
}

\author{
Alan T. Villavicencio, MD, ${ }^{1,2}$ E. Lee Nelson, MD, ${ }^{1}$ Vinod Kantha, BA, ${ }^{2}$ and Sigita Burneikiene, MD ${ }^{1,2}$ \\ 'Boulder Neurosurgical Associates and 2Justin Parker Neurological Institute, Boulder, Colorado
}

OBJECTIVE Opioid analgesics have become some of the most prescribed drugs in the world, despite the lack of longterm studies evaluating the benefits of opioid medications versus their risks associated with chronic use. In addition, long-term opioid use may be associated with worse long-term clinical outcomes. The primary objective of this study was to evaluate whether preoperative opioid use predicted inferior clinical outcomes among patients undergoing transforaminal lumbar interbody fusion (TLIF) for symptomatic lumbar degenerative disc disease.

METHODS The authors of this observational study prospectively enrolled 93 patients who underwent 1-level to 2-level TLIFs in 2011-2014; the patient cohort was divided into 2 groups according to preoperative opioid use or no such use. Visual analog scale (VAS) scores for low-back pain and leg pain, Oswestry Disability Index scores, and the scores of the mental component summary (MCS) and physical component summary (PCS) on the 36-Item Short Form Health Survey were used to assess pain, disability, and health-related quality of life outcomes, respectively. The clinical scores for the 2 groups were determined preoperatively and at a 12-month follow-up examination.

RESULTS In total, 60 (64.5\%) patients took prescribed opioid medications preoperatively. Compared with those not taking opioids preoperatively, these patients had significantly higher VAS scores for low-back pain $(p=0.016)$, greater disability $(p=0.013)$, and lower PCS scores $(p=0.03)$ at the 12-month follow-up. The postoperative MCS scores were also significantly lower $(p=0.035)$ in the opioid-use group, but these lower scores were due to significantly lower baseline MCS scores in this group. A linear regression analysis did not detect opioid dose-related effects on leg and back pain, disability, and MCS and PCS scores, suggesting that poorer outcomes are not significantly correlated with higher opioid doses taken by the patients.

CONCLUSIONS The use of opioid medications to control pain before patients underwent lumbar fusion for degenerative lumbar conditions was associated with less favorable clinical outcomes postoperatively. This is the first study that has demonstrated this association in a homogeneous cohort of patients undergoing TLIF; this association should be studied further to evaluate the conclusions of the present study.

Clinical trial registration no.: NCT01406405 (clinicaltrials.gov)

https://thejns.org/doi/abs/10.3171/2016.7.SPINE16284

KEY WORDS clinical outcomes; opioid medications; transforaminal lumbar interbody fusion

$\mathrm{O}$ PIOID analgesics have become some of the most frequently prescribed medications in the world, and almost $100 \%$ of the total hydrocodone and $83 \%$ of oxycodone are consumed in the United States. ${ }^{13}$ Multiple factors have contributed to the current levels of opioid prescribing, but one of them is that the threshold for prescribing these pain medications for chronic pain is decreasing in the United States despite a lack of long-term studies evaluating the benefits versus risks of opioid medications for managing chronic pain. ${ }^{7}$ The evidence that opi- oids are effective for managing chronic low-back pain is mostly based on population studies ${ }^{11}$ and on short-term or uncontrolled studies. ${ }^{4,14,26}$ Some studies have reported that long-term opioid use or early opioid prescribing practices may be not only ineffective but even counterproductive to recovery because opioid use may be associated with worse long-term clinical outcomes, prolonged disability, increased use of medical resources, and continued opioidbased medication use. ${ }^{27}$ A preoperative use of opioid analgesics has previously been found to be a negative pre-

ABBREVIATIONS MCS = mental component summary; ODI = Oswestry Disability Index; PCS = physical component summary; SF-36 = 36-Item Short Form Health Survey; TLIF = transforaminal lumbar interbody fusion; VAS = visual analog scale.

SUBMITTED March 9, 2016. ACCEPTED July 12, 2016.

INCLUDE WHEN CITING Published online September 30, 2016; DOI: 10.3171/2016.7.SPINE16284. 
dictive factor among patients undergoing gynecological, ${ }^{25}$ total knee ${ }^{28}$ or hip arthroplasty, ${ }^{20}$ or spine surgery. ${ }^{16,17}$

The main objective of the present study was to assess a relationship between preoperative use of analgesic opioid medications and clinical outcomes for patients undergoing transforaminal lumbar interbody fusion (TLIF) for degenerative low-back pain conditions.

\section{Methods \\ Patient Selection and Characteristics}

We initiated a prospective observational study and enrolled 93 consecutive patients who underwent elective TLIF at 1 or 2 adjacent spinal levels for symptomatic lumbar degenerative disc disease. For this study, we included patients with no previous fusion surgeries and who predominantly had radicular pain due to degenerative disc disease and stenosis with spondylolisthesis. The surgeries were performed by 5 surgeons in the period of September 2011-December 2014 at a single institution. Degenerative disc disease in the patients had been unresponsive to conservative care over a period of at least 6 months, or patients had progressive neurological signs or symptoms of neurological compromise that mandated urgent surgical intervention. The patients were divided into 2 groups according to preoperative opioid use. Each patient's total daily opioid dose consumption was converted to a standardized morphine-equivalent dose.

\section{Assessments of Clinical Outcomes}

We used standardized questionnaires to evaluate clinical outcomes. Health-related quality of life and functional outcomes were assessed with the 36-Item Short Form Health Survey (SF-36). Two scores within the scoring algorithm were analyzed: those of the physical component summary (PCS) and the mental component summary (MCS). The Oswestry Disability Index (ODI) was used to evaluate chronic disability and activities of daily living. The severities of low-back and leg pain were measured with visual analog scales (VASs).

\section{Statistical Analysis}

Multivariate logistic regression analysis was used to examine the relationship of preoperative opioid medication use with clinical outcome scores at the 12-month followup. The analysis controlled for the following independent variables: number of surgical levels, baseline scores, age, previous surgeries, and comorbidities. Comorbidities were stratified into 4 separate categories: general (e.g., obesity, diabetes, cancer, or liver or renal disease), addictions and mental health (e.g., depression or drug or alcohol abuse), cardiac related (e.g., congestive heart failure, myocardial infarction, or arrhythmias), and circulatory vascular comorbidities (e.g., cerebrovascular or coronary artery disease).

Other preoperative and intraoperative factors were analyzed using Student t-tests for all independent continuous quantitative variables (i.e., symptom duration, estimated blood loss, time in the operating room, and length of stay in the hospital) or with the chi-square test for categorical values (i.e., sex, diagnosis, and complications).

\section{Results \\ General Patient Characteristics}

In total, 60 patients $(64.5 \%)$ regularly used prescribed opioid medications before undergoing TLIF. The mean preoperative 24-hour morphine-equivalent dose for these patients was $65.4 \pm 50.9 \mathrm{mg}$ (range 10-270 mg). The baseline demographic and surgical characteristics of all patients are shown in Table 1. No statistically significant differences were observed between the opioid-using and nonusing patient groups, except for duration of symptoms of lumbar degenerative disc disease: the patients who did not use opioid medications preoperatively had symptoms that lasted twice as long as those of the patients who took opioids ( $\mathrm{p}=0.008)$, but the 2 patient groups had similar preoperative diagnoses. Although not statistically significant $(\mathrm{p}=0.11)$, a somewhat higher percentage of patients who did not use opioid medications before surgery were undergoing 2-level TLIFs. Surgical parameters were also comparable between the 2 groups, except that operative times tended to be longer for the patients who did not use opioid medications preoperatively $(\mathrm{p}=0.07)$. This longer operative time was most likely due to a higher percentage of 2-level TLIFs in this patient group.

\section{Clinical Scores and Outcomes}

A comparison of preoperative clinical scores (Table 2) did not detect statistically significant differences in SF-36 PCS scores and in low-back pain and leg pain VAS scores between the patients who took opioid analgesics preoperatively and those who did not; however, the patients who used opioids had significantly higher ODI scores and lower SF-36 MCS scores. We performed a Pearson correlation analysis to measure the strength of the association between these 2 latter variables. The lower preoperative MCS scores were significantly correlated with greater preoperative disability, regardless of opioid use (Fig. 1). This finding confirmed that a low back-related disability score directly correlates with quality of life assessment scores representing patient-perceived mental dysfunction.

A comparison of preoperative and postoperative clinical outcome scores indicated that all patients had statistically highly significant postoperative improvements $(\mathrm{p}<$ 0.0001) in back and leg pain, disability, and PCS scores. Interestingly, we observed a more significant improvement $(\mathrm{p}<0.0001)$ in the MCS scores among patients who took opioids before surgery than among the patients who did not $(\mathrm{p}=0.03)$. But a greater improvement was also true for all the preoperative scores in general, regardless of opioid medication use-the greater the degree of preoperative impairment, the greater the extent of postoperative improvement on the same scale was noted. When the difference was calculated between the preoperative and postoperative scores, the patients who had a preoperative back pain score of greater than 6 had much better pain improvement than the patients who had a back pain score of less than 6 preoperatively (5.1 vs 1.6 points, $\mathrm{p}<0.0001$ ). Similar results were observed for leg pain (5.8 vs 1.4 , p < 0.0001 ) and also ODI scores: patients with more than $40 \%$ disability had more significant improvement in disability (26.8 vs $13.6, \mathrm{p}=0.0002$ ). We conclude that even though 
TABLE 1. Baseline demographic and surgical characteristics

\begin{tabular}{|c|c|c|c|}
\hline \multirow[b]{2}{*}{ Variable } & \multicolumn{2}{|c|}{ Patients } & \multirow[b]{2}{*}{$\begin{array}{c}p \\
\text { Value }\end{array}$} \\
\hline & $\begin{array}{l}\text { Preop Opioid } \\
\text { Users }(n=60)\end{array}$ & $\begin{array}{c}\text { Nonusers } \\
(n=33)\end{array}$ & \\
\hline Age in yrs (range) & $59.8(32-81)$ & $59.6(32-77)$ & 0.940 \\
\hline F/M ratio & $31: 29$ & 18:15 & $0.830^{*}$ \\
\hline $\begin{array}{l}\text { Symptom duration in } \\
\text { mos (range) }\end{array}$ & $56(0.3-300)$ & $113(0.3-480)$ & 0.008 \\
\hline \multicolumn{4}{|l|}{ Previous surgeries } \\
\hline Microdiscectomy & $10(16.7)$ & $3(9.1)$ & $0.360^{*}$ \\
\hline $\begin{array}{l}\text { Decompression/lami- } \\
\text { nectomy }\end{array}$ & $5(8.3)$ & $3(9.1)$ & $1.000^{*}$ \\
\hline Dynamic fixation & $0(0.0)$ & $1(3.0)$ & $0.360^{*}$ \\
\hline Rhizotomy & $1(1.7)$ & $0(0.0)$ & $1.000^{*}$ \\
\hline \multicolumn{4}{|l|}{ Diagnosis } \\
\hline Radicular symptoms & $58(96.7)$ & $30(90.9)$ & $0.340^{*}$ \\
\hline Spinal stenosis & $33(55.0)$ & $20(60.6)$ & $0.670^{*}$ \\
\hline Spondylolisthesis & $32(53.3)$ & $19(57.6)$ & $0.830^{*}$ \\
\hline Scoliosis & $5(8.3)$ & $6(18.2)$ & $0.190^{*}$ \\
\hline Comorbidities & & & 0.870 \\
\hline General & $42(70.0)$ & $20(60.6)$ & \\
\hline $\begin{array}{l}\text { Addiction \& mental } \\
\text { health }\end{array}$ & $20(33.3)$ & $12(36.4)$ & \\
\hline Cardiac related & $21(35.0)$ & $10(30.3)$ & \\
\hline Circulatory \& vascular & $33(55.0)$ & $18(54.6)$ & \\
\hline Surgical characteristics & & & 0.110 \\
\hline 1-level TLIFs & $44(73.3)$ & $18(54.6)$ & \\
\hline L2-3 & 1 & 1 & \\
\hline L3-4 & 2 & 1 & \\
\hline L4-5 & 25 & 10 & \\
\hline L5-S1 & 16 & 6 & \\
\hline 2-level TLIFs & $16(26.7)$ & $15(45.4)$ & \\
\hline L3-5 & 4 & 7 & \\
\hline L4-S1 & 12 & 8 & \\
\hline \multicolumn{4}{|l|}{ Surgical parameters } \\
\hline EBL in $\mathrm{ml}$ (range) & $150(25-750)$ & $185(50-700)$ & 0.290 \\
\hline $\begin{array}{l}\text { OR time in mins } \\
\text { (range) }\end{array}$ & $159(81-344)$ & $181(108-266)$ & 0.070 \\
\hline LOS in days (range) & $1.9(0.0-10.0)$ & $1.9(0.0-8.0)$ & 0.900 \\
\hline
\end{tabular}

$\mathrm{EBL}=$ estimated blood loss; $\mathrm{LOS}=$ length of stay; $\mathrm{OR}=$ operating room. Unless indicated otherwise, values represent means (\%); $p$ values were determined with Student t-tests, except where indicated otherwise.

${ }^{*} \mathrm{p}$ value was determined with the Fisher exact test.

significantly higher disability scores were detected preoperatively for the patients who used opioid medications, these scores did not solely and adversely affect clinical outcomes.

We next performed multivariate logistic regression analysis of the clinical outcomes at the 12-month followup. This analysis controlled for the number of spinal levels, baseline scores, age, previous surgeries, and comorbidities and detected statistically significantly higher low-back pain scores $(\mathrm{p}=0.016)$ and ODI scores $(\mathrm{p}=0.013)$ and
TABLE 2. Preoperative clinical scores

\begin{tabular}{lccc}
\hline & \multicolumn{2}{c}{ Patients } & \\
\cline { 2 - 3 } Clinical Score & $\begin{array}{c}\text { Preop Opioid } \\
\text { Users }\end{array}$ & Nonusers & Value \\
\hline Back pain VAS & $6.5(0.0-7.0)$ & $6.0(3.0-10.0)$ & 0.390 \\
\hline Leg pain VAS & $5.5(0.0-10.0)$ & $5.1(0.0-10.0)$ & 0.600 \\
\hline ODI & $40.3(6.0-78.0)$ & $33.7(14.0-66.0)$ & 0.040 \\
\hline SF-36 MCS & $42.7(17.3-63.6)$ & $49.2(19.5-68.0)$ & 0.012 \\
\hline SF-36 PCS & $32.1(13.4-51.1)$ & $34.4(20.1-49.3)$ & 0.190 \\
\hline
\end{tabular}

Values represent means and ranges; $p$ values were determined with Student t-tests.

lower PCS scores $(p=0.03)$ among the patients who used opioids preoperatively than among those who did not. The postoperative MCS scores were also significantly lower in the opioid-use group $(p=0.035)$, but these lower scores were due to the significantly lower preoperative MCS scores $(\mathrm{p}=0.01)$ in this group (Table 3$)$.

The differences in postoperative leg pain scores $(\mathrm{p}=$ 0.061) did not quite reach statistical significance. The only other variable that played some role in clinical outcomes, namely, in ODI and PCS scores, was the number of spinal levels $(\mathrm{p}=0.061$ and $\mathrm{p}=0.016$, respectively) (Table 3). However, although not statistically significant in the chi-square test, we noted a higher percentage of patients who had 2-level TLIFs in the patient group who did not use opioids preoperatively. The postoperative clinical outcome scores are summarized in Table 4 . The 2 groups did not statistically significantly differ in perioperative complication rates (Table 5).

\section{Relationship Between Opioid Dose and Clinical Outcomes}

Because the group of patients with preoperative opioid users was quite heterogeneous, and the opioid doses taken by the patients ranged from 10 to $270 \mathrm{mg}$ morphineequivalent dose, the Pearson regression coefficient and $\mathrm{p}$ values (significance level $=0.05$ ) were calculated for independent opioid dose and dependent outcome variables to determine if a linear relationship existed between these variables. No statistically significant correlations were detected of opioid dose with back pain score $(r=0.0351, \mathrm{p}$ $=0.81)$, leg pain score $(\mathrm{r}=-0.0066, \mathrm{p}=0.97)$, ODI score $(\mathrm{r}=0.1188, \mathrm{p}=0.42)$, PCS score $(\mathrm{r}=0.0176, \mathrm{p}=0.91)$, and MCS score $(r=0.0168, p=0.91)$. This analysis suggested that there were no opioid dose-related effects and that poorer outcomes were apparently not related to higher opioid doses taken by the patients.

\section{Discussion}

The results of the present study indicate that although all patients had significant improvement after TLIF for lumbar degenerative disc disease, the patients who did not use opioid analgesics preoperatively had significantly better clinical outcome scores at the 12-month follow-up than those who took opioid medications. This observation held true despite the fact that the nonusers had disease symptoms that lasted twice as long and were undergoing a slightly higher percentage of 2-level surgeries. In addi- 


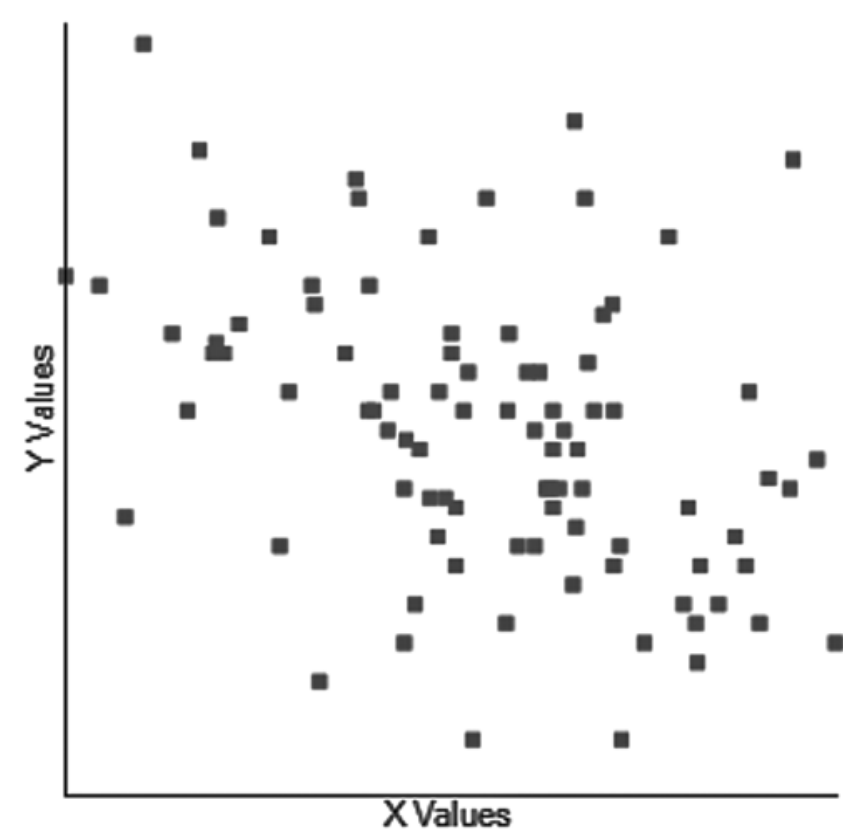

FIG. 1. Correlation of preoperative SF-36 MCS scores with ODI scores. Lower MCS scores (x-axis) were significantly and negatively correlated with higher ODI scores (y-axis) $(r=-0.41, p<0.05)$.

tion, a close correlation was observed between preoperative opioid medication use and low SF-36 MCS scores ( $p$ $=0.012$ ), which improved very significantly after surgery, but were still lower than those of the patients who did not use opioids preoperatively.

We previously evaluated the effect of preoperative MCS scores and patient pain expectancies on clinical outcomes, ${ }^{5}$ but we did not analyze the causes of lower MCS scores. The association of lower preoperative MCS scores and inferior clinical outcomes is well documented, ${ }^{6,8,9,24}$ and both mental wellbeing and opioid use most likely play a significant role in these outcomes. This study also could not answer the question whether patients who have greater back pain and lower MCS scores are more inclined to use opioid pain relievers or whether the use of these medications primarily affects MCS scores. However, the results of the present study contribute to existing evidence that mental health may be affected by opioid use and that such use is related to inferior clinical outcomes in patients with degenerative disc disease and radiculopathy symptoms.

Multiple studies have evaluated the factors predictive of good clinical outcomes after lumbar surgeries, including sociodemographic variables (such as age, sex, body mass index, education level, and smoking) $)^{6,89}$ or clinical and psychological factors. ${ }^{3,8-10,12,15,21,24}$ It is generally accepted that better mental and emotional health (e.g., higher preoperative MCS scores) correlate with improved clinical outcomes. In contrast, all studies published to date that specifically analyzed correlations between preoperative opioid medication use and clinical outcomes in patients who had undergone spine surgeries reported that opioid use was a negative predictor of these outcomes. ${ }^{16,17,27} \mathrm{In}$ creased preoperative opioid consumption as well as higher preoperative scores on the modified somatic perception questionnaire and the Zung Depression Scale were signifi-
TABLE 3. Summary of multivariate logistic regression analysis to identify differences in postoperative outcomes between opioid users and nonusers

\begin{tabular}{|c|c|c|}
\hline Measure & Odds Ratio $(95 \% \mathrm{Cl})$ & $p$ Value \\
\hline \multicolumn{3}{|l|}{ Postop back pain } \\
\hline Preop back pain & $1.06(0.87-1.28)$ & 0.584 \\
\hline Age & $1.00(0.94-1.05)$ & 0.928 \\
\hline Previous surgeries & $1.63(0.50-5.34)$ & 0.421 \\
\hline Spinal levels & $0.44(0.19-1.07)$ & 0.069 \\
\hline Comorbidities & $\begin{array}{l}0.46(0.07-0.74) \text { to } \\
3.50(2.94-16.52)\end{array}$ & $\geq 0.114$ \\
\hline \multicolumn{3}{|l|}{ Postop leg pain } \\
\hline Preop leg pain & $1.00(0.86-1.16)$ & 0.998 \\
\hline Age & $1.00(0.96-1.04)$ & 0.901 \\
\hline Previous surgeries & $0.56(0.25-1.26)$ & 0.162 \\
\hline Spinal levels & $1.48(0.53-4.18)$ & 0.456 \\
\hline Comorbidities & $\begin{array}{l}0.54(0.10-0.57) \text { to } \\
2.02(1.60-7.14)\end{array}$ & $\geq 0.273$ \\
\hline \multicolumn{3}{|l|}{ Postop ODI score } \\
\hline Preop ODI score & $1.02(0.99-1.06)$ & 0.201 \\
\hline Age & $0.98(0.93-1.04)$ & 0.585 \\
\hline Previous surgeries & $1.76(0.53-5.81)$ & 0.357 \\
\hline Spinal levels & $0.38(0.15-0.96)$ & 0.061 \\
\hline Comorbidities & $\begin{array}{l}0.48(0.08-0.67) \text { to } \\
3.15(3.02-14.81)\end{array}$ & $\geq 0.147$ \\
\hline \multicolumn{3}{|l|}{ Postop SF-36 PCS } \\
\hline Preop SF-36 PCS & $0.997(0.997-1.040)$ & 0.919 \\
\hline Age & $0.99(0.95-1.03)$ & 0.597 \\
\hline Previous surgeries & $1.42(0.49-4.16)$ & 0.519 \\
\hline Spinal levels & $0.41(0.17-0.99)$ & 0.016 \\
\hline Comorbidities & $\begin{array}{l}0.31(0.05-0.57) \text { to } \\
2.11(1.87-7.82)\end{array}$ & $\geq 0.206$ \\
\hline \multicolumn{3}{|l|}{ Postop SF-36 MCS } \\
\hline Preop SF-36 MCS & $0.94(0.89-0.98)$ & 0.010 \\
\hline Age & $0.99(0.93-1.05)$ & 0.710 \\
\hline Previous surgeries & $1.23(0.39-3.93)$ & 0.722 \\
\hline Spinal levels & $0.52(0.21-1.28)$ & 0.157 \\
\hline Comorbidities & $\begin{array}{l}0.40(0.06-0.51) \text { to } \\
1.99(1.48-8.62)\end{array}$ & $\geq 0.293$ \\
\hline
\end{tabular}

cant predictors of worse clinical outcomes in a study that included 583 patients who underwent surgeries ranging from microdiscectomies to fusion and deformity corrections. ${ }^{17}$ Although the authors controlled for invasiveness of the surgery, the study included patients with lumbar, thoracolumbar, and cervical procedures, as well as repeat surgeries, and this inclusion might have caused bias in the estimate of the impact on the outcomes studied.

Lawrence et al., ${ }^{16}$ reporting on a cohort of patients undergoing cervical arthrodesis, observed significantly worse clinical outcomes and continued postoperative opioid use among patients who had used opioids preoperatively. The authors suggested that patients should discontinue opioid medication use before surgery and also undergo a 
TABLE 4. Postoperative clinical outcome scores

\begin{tabular}{lccc}
\hline & \multicolumn{2}{c}{ Patients } & \\
\cline { 2 - 3 } \multicolumn{1}{c}{ Score } & \multicolumn{1}{c}{$\begin{array}{c}\text { Preop Opioid } \\
\text { Users }\end{array}$} & Nonusers & Value \\
\hline Back pain VAS & $2.5(0-8)$ & $1.5(0-6)$ & 0.042 \\
\hline Leg pain VAS & $1.5(0-8)$ & $0.6(0-3)$ & 0.038 \\
\hline ODI & $17.5(0-48)$ & $10.3(0-42)$ & 0.015 \\
\hline SF-36 MCS & $51.4(20.5-64.7)$ & $55.1(25.2-63.9)$ & 0.096 \\
\hline SF-36 PCS & $44.7(20.8-61.4)$ & $49.6(33.4-59)$ & 0.016 \\
\hline
\end{tabular}

Values represent means (range); $p$ values were determined with Student t-tests.

formal detoxification treatment, but they also noted that it is uncertain whether such measures would reverse the adverse effects of preoperative opioid use. Another retrospective analysis, involving an administrative database of 8443 claims for workers' compensation, ${ }^{27}$ showed that when opioids were prescribed within the first 15 days of a patient's diagnosis of acute occupational low-back pain, this prescription was associated with worse long-term outcomes, continued opioid use, and greater use of health care services, including surgery, and led to higher medical costs. In the group of patients who had received the highest opioid doses, the risk for surgery was 3 times that of those who had received no opioids.

Other studies that did not specifically analyze a correlation between preoperative opioid use and clinical outcomes in patients undergoing lumbar surgery or conservative treatment have failed to show any detrimental effects of preoperative opioid medication use ${ }^{8,19}$ or showed significance only for weak opioid-based pain medications in patients undergoing anterior cervical discectomy and fusion surgeries. ${ }^{1}$ Armaghani et al. ${ }^{3}$ noted that patients undergoing spine surgery are predisposed to higher preoperative opioid use because of underlying psychological conditions related to their health. But the opposite may also be true: longer than 30-day use of opioid analgesics was associated with new-onset of depression regardless of opioid dose..$^{22}$

The reasons for the worse outcomes among patients who use opioid pain relievers are multifactorial, but opioid-induced hyperalgesia ${ }^{2,18,23}$ most likely plays an important role. Hyperalgesia has been described as a paradoxical response and a state of nociceptive sensitization, resulting in pain chronicization processes caused by opioid exposure. Clinical implications of this phenomenon cannot be underestimated in the management of chronic pain conditions. The use of opioid medications is a potentially modifiable factor that could be controlled to maximize clinical outcomes. Keeping in mind that preoperative opioid use may be detrimental to the surgical outcomes, health care providers should use a multimodal approach or alternative means of pain control when possible to reduce patients' consumption of opioids.

\section{Limitations}

The main limitations for this study were that patients were not randomized to pain treatment and that the sample of 93 patients was small. However, our study design
TABLE 5. Perioperative complications

\begin{tabular}{lccc}
\hline & \multicolumn{2}{c}{ No. of Patients } & \\
\cline { 2 - 3 } \multicolumn{1}{c}{ Complication } & $\begin{array}{c}\text { Preop Opioid } \\
\text { Users (\%) }\end{array}$ & $\begin{array}{c}\text { Nonusers } \\
(\%)\end{array}$ & $\begin{array}{c}p \\
\text { Value }\end{array}$ \\
\hline Infections & $3(5.0)$ & $2(6.0)$ & 1.00 \\
\hline CSF leak & $1(1.7)$ & $3(9.1)$ & 0.13 \\
\hline Pedicle fracture & $0(0.0)$ & $2(6.0)$ & 0.12 \\
\hline Hardware malpositioning & $3(5.0)$ & $2(6.0)$ & 1.00 \\
\hline
\end{tabular}

$p$ values were determined with the Fisher exact test.

helped minimize bias due to heterogeneity, as only patients with no previous lumbar fusions and undergoing 1-level or 2-level TLIFs were enrolled in the present series. We note that it would be very difficult to perform a randomized controlled study in this patient population, and it is unlikely that such studies could be conducted soon.

We also note that although we detected statically significant differences between the 2 groups, not all of the clinical outcomes tested reached a minimal clinically important difference. This lack of clinically significant differences was likely caused by slightly underpowered postoperative leg and back pain scores; the post hoc power for these scores was $49.7 \%$ and $70.3 \%$, respectively. In contrast, it was $80.1 \%$ for the postoperative ODI scores and $89.8 \%$ for the PCS scores. The lack of statistical power could also be one of the reasons why postoperative leg pain scores did not quite reach statistical significance in the logistic multiple regression analysis. Although statistically significant differences were detected in Student t-tests, this analysis was affected by the slightly higher number of 2-level TLIF surgeries in the patients who did not use opioid medications preoperatively.

Some limitations of the present study that could have been avoided are the lack of information on the duration of preoperative opioid medication use and on the use for pain control past the immediate postoperative period. This information was not collected prospectively, and retrospective data were too unreliable to be analyzed. Another limitation of this study was the relatively short follow-up length of 12 months. However, the shorter follow-up allowed us to assess clinical outcomes and minimize confounding factors unavoidable in longer-term clinical studies, such as those related to any symptoms due to disc degeneration at adjacent segments over time.

\section{Conclusions}

Patients' use of opioid medications to control pain before undergoing lumbar fusion for degenerative lumbar disc conditions was associated with less favorable clinical outcomes postoperatively. This is the first study that has demonstrated this association in a homogeneous population of patients, and this association should be studied further to evaluate our conclusions.

\section{Acknowledgments}

We would like to thank Dominykas Burneikis, MD, for conducting the statistical analysis. 


\section{References}

1. Anderson PA, Subach BR, Riew KD: Predictors of outcome after anterior cervical discectomy and fusion: a multivariate analysis. Spine (Phila Pa 1976) 34:161-166, 2009

2. Angst MS, Clark JD: Opioid-induced hyperalgesia: a qualitative systematic review. Anesthesiology 104:570-587, 2006

3. Armaghani SJ, Lee DS, Bible JE, Archer KR, Shau DN, Kay $\mathrm{H}$, et al: Preoperative narcotic use and its relation to depression and anxiety in patients undergoing spine surgery. Spine (Phila Pa 1976) 38:2196-2200, 2013

4. Buynak R, Shapiro DY, Okamoto A, Van Hove I, Rauschkolb C, Steup A, et al: Efficacy and safety of tapentadol extended release for the management of chronic low back pain: results of a prospective, randomized, double-blind, placebo- and active-controlled Phase III study. Expert Opin Pharmacother 11:1787-1804, 2010

5. Carr FA, Healy KM, Villavicencio AT, Nelson EL, Mason A, Burneikiene S, et al: Effect on clinical outcomes of patient pain expectancies and preoperative Mental Component Summary scores from the 36-Item Short Form Health Survey following anterior cervical discectomy and fusion. J Neurosurg Spine 15:486-490, 2011

6. Carreon LY, Glassman SD, Djurasovic M, Dimar JR, Johnson JR, Puno RM, et al: Are preoperative health-related quality of life scores predictive of clinical outcomes after lumbar fusion? Spine (Phila Pa 1976) 34:725-730, 2009

7. Chou R, Turner JA, Devine EB, Hansen RN, Sullivan SD, Blazina I, et al: The effectiveness and risks of long-term opioid therapy for chronic pain: a systematic review for a National Institutes of Health Pathways to Prevention Workshop. Ann Intern Med 162:276-286, 2015

8. Cobo Soriano J, Sendino Revuelta M, Fabregate Fuente M, Cimarra Díaz I, Martínez Ureña P, Deglané Meneses R: Predictors of outcome after decompressive lumbar surgery and instrumented posterolateral fusion. Eur Spine J 19:18411848,2010

9. Derby R, Lettice JJ, Kula TA, Lee SH, Seo KS, Kim BJ: Single-level lumbar fusion in chronic discogenic low-back pain: psychological and emotional status as a predictor of outcome measured using the 36-item Short Form. J Neurosurg Spine 3:255-261, 2005

10. Deutsch H: The predictive value of the baseline Oswestry Disability Index in lumbar disc arthroplasty. Neurosurg Focus 28(6):E7, 2010

11. Eriksen J, Jensen MK, Sjøgren P, Ekholm O, Rasmussen NK: Epidemiology of chronic non-malignant pain in Denmark. Pain 106:221-228, 2003

12. Hägg O, Fritzell P, Ekselius L, Nordwall A: Predictors of outcome in fusion surgery for chronic low back pain. A report from the Swedish Lumbar Spine Study. Eur Spine J 12:22-33, 2003

13. International Narcotics Control Board: Report of the International Narcotics Control Board for 2008. New York: United Nations, 2009

14. Jamison RN, Raymond SA, Slawsby EA, Nedeljkovic SS, Katz NP: Opioid therapy for chronic noncancer back pain. A randomized prospective study. Spine (Phila Pa 1976) 23:2591-2600, 1998

15. Katz JN, Lipson SJ, Brick GW, Grobler LJ, Weinstein JN, Fossel AH, et al: Clinical correlates of patient satisfaction after laminectomy for degenerative lumbar spinal stenosis. Spine (Phila Pa 1976) 20:1155-1160, 1995

16. Lawrence JT, London N, Bohlman HH, Chin KR: Preoperative narcotic use as a predictor of clinical outcome: results following anterior cervical arthrodesis. Spine (Phila Pa 1976) 33:2074-2078, 2008
17. Lee D, Armaghani S, Archer KR, Bible J, Shau D, Kay H, et al: Preoperative opioid use as a predictor of adverse postoperative self-reported outcomes in patients undergoing spine surgery. J Bone Joint Surg Am 96:e89, 2014

18. Lee M, Silverman SM, Hansen H, Patel VB, Manchikanti L: A comprehensive review of opioid-induced hyperalgesia. Pain Physician 14:145-161, 2011

19. Pearson A, Lurie J, Tosteson T, Zhao W, Abdu W, Weinstein JN: Who should have surgery for spinal stenosis? Treatment effect predictors in SPORT. Spine (Phila Pa 1976) 37:17911802, 2012

20. Pivec R, Issa K, Naziri Q, Kapadia BH, Bonutti PM, Mont MA: Opioid use prior to total hip arthroplasty leads to worse clinical outcomes. Int Orthop 38:1159-1165, 2014

21. Saberi H, Isfahani AV: Higher preoperative Oswestry Disability Index is associated with better surgical outcome in upper lumbar disc herniations. Eur Spine J 17:117-121, 2008

22. Scherrer JF, Salas J, Copeland LA, Stock EM, Ahmedani BK, Sullivan MD, et al: Prescription opioid duration, dose, and increased risk of depression in 3 large patient populations. Ann Fam Med 14:54-62, 2016

23. Simonnet G, Rivat C: Opioid-induced hyperalgesia: abnormal or normal pain? Neuroreport 14:1-7, 2003

24. Trief PM, Ploutz-Snyder R, Fredrickson BE: Emotional health predicts pain and function after fusion: a prospective multicenter study. Spine (Phila Pa 1976) 31:823-830, 2006

25. VanDenKerkhof EG, Hopman WM, Goldstein DH, Wilson RA, Towheed TE, Lam M, et al: Impact of perioperative pain intensity, pain qualities, and opioid use on chronic pain after surgery: a prospective cohort study. Reg Anesth Pain Med 37:19-27, 2012

26. Vorsanger GJ, Xiang J, Gana TJ, Pascual ML, Fleming RR: Extended-release tramadol (tramadol ER) in the treatment of chronic low back pain. J Opioid Manag 4:87-97, 2008

27. Webster BS, Verma SK, Gatchel RJ: Relationship between early opioid prescribing for acute occupational low back pain and disability duration, medical costs, subsequent surgery and late opioid use. Spine (Phila Pa 1976) 32:2127-2132, 2007

28. Zywiel MG, Stroh DA, Lee SY, Bonutti PM, Mont MA: Chronic opioid use prior to total knee arthroplasty. J Bone Joint Surg Am 93:1988-1993, 2011

\section{Disclosures}

The authors report no conflict of interest concerning the materials or methods used in this study or the findings specified in this paper.

\section{Author Contributions}

Conception and design: Burneikiene, Villavicencio. Acquisition of data: Villavicencio, Nelson, Kantha. Analysis and interpretation of data: Burneikiene. Drafting the article: Burneikiene. Critically revising the article: Villavicencio, Nelson. Reviewed submitted version of manuscript: all authors. Approved the final version of the manuscript on behalf of all authors: Burneikiene. Statistical analysis: Burneikiene. Administrative/technical/material support: Kantha. Study supervision: Burneikiene.

\section{Correspondence}

Sigita Burneikiene, Boulder Neurosurgical Associates, 4743 Arapahoe Ave., Ste. 202, Boulder, CO 80303.email: sigitab@ bnasurg.com. 